\title{
Optimization of an Extraction Procedure for the Accurate Determination of Total Tin in Eighteen Geological Survey of Japan Rock Reference Materials
}

\author{
H. N. ELSHEIMER \\ U. S. Geological Survey, Menlo Park, CA 94025, USA
}

\begin{abstract}
A fusion-extraction procedure for the determination of total tin in rocks and sediments by graphite furnace atomic absorption spectrometry (GFAAS) was reexamined and modified to obtain the optimum accuracy and precision. Several variations based on increases in the sample weight or extraction ratio were compared based on the determination of tin in 18 Geological Survey of Japan (GSJ) reference materials. The most accurate and precise procedure was found to be an $8: 1$ extraction of a $0.5 \mathrm{~g}$ rock sample fused with lithium metaborate and dissolved in $7.5 \%$ hydrochloric acid, using a $4 \%$ solution of trioctylphosphine oxide in methyl isobutyl ketone (TOPO-MIBK). Rocks containing $<1 \mu \mathrm{g} / \mathrm{g}$ total tin require a $0.5 \mathrm{~g}$ sample size for the utmost accuracy. Utilizing these modifications, tin concentrations were found to be within $0.1 \mu \mathrm{g} / \mathrm{g}$ for all of the GSJ reference standards with the exception of the rhyolites. Values are reported for the total tin content of three new GSJ reference materials, namely, JLk-1, JLs-1, and JDo-1.
\end{abstract}

Keywords Total tin, graphite furnace atomic absorption spectrometry, extraction, rock reference materials, statistics, trioctylphosphine oxide-methyl isobutyl ketone

The most prevalent methods in recent years for the determination of total tin in rocks, soils, and sediments have utilized atomic absorption spectrometry (AAS) and its variations: flame, flame/hydride, or graphite furnace spectrometry. Fritzsche et al. ${ }^{1}$, Lundberg et $a l .{ }^{2}$, Pruszkowska et $a l .^{3}$, Long-zhu ${ }^{4}$, and Zhou et al. ${ }^{5}$ have all made significant contributions to improving the determination of total tin in rocks and sediments by graphite furnace techniques. This author ${ }^{6}$ modified the procedure developed by Zhou and coworkers by using graphite crucibles instead of platinum, a lower acid concentration, a magnesium nitrate/ammonium phosphate matrix modifier for signal enhancement, and pyrolytically coated graphite tubes and platforms rather than tungsten-impregnated graphite tubes. Eight international geological reference standards were analyzed to validate the method, and application was made to the analysis of 230 geologic rock core samples from a platinum group element-enriched, layered, intrusive deposit. The improvements resulting from our modifications were a more rapid method with enhanced sensitivity and greater precision and accuracy.

Subsequent to the initial work in this laboratory, other combinations of extraction ratios and sample weights were tried with the goal of determining the optimum conditions for most rock types. That optimization is the subject of this paper, which evaluates several combinations of extraction ratio and sample size. Eighteen GSJ reference materials which included silicate rocks, carbonate rocks, and a sediment were analyzed for the purposes of comparison. Three of these (JLk-1, JLs-1, and JDo-1) have no previously reported values for tin content. The values obtained for the other standards were compared with the recommended values reported by Govindaraju in $1984^{7}$ and $1989 .{ }^{8}$

\section{Experimental}

\section{Apparatus*}

A Perkin-Elmer 5100 series AA spectrophotometer with Zeeman background correction was utilized for this work. The system included a stabilized temperature platform graphite furnace (STPF), a Perkin-Elmer AS60 autosampler, a Perkin-Elmer PR 310 printer, and a Perkin-Elmer 7700 professional computer. A tin hollow-cathode lamp was used as a light source. The following programmed settings were used: wavelength, $286.3 \mathrm{~nm}$; lamp current, $13 \mathrm{~mA}$; energy $53-55 \%$; spectral bandwidth, $0.7 \mathrm{~nm}$; integration time, $5 \mathrm{~s}$; readout mode, peak area. The atomization program is shown in Table 1. One modification of the original work $^{6}$ was to extend the charring period by slowly ramping (35 s) to $280^{\circ} \mathrm{C}$, and then making a moderately

* Trade names \& company names are for identification purposes only and do not imply endorsement by the U.S. Geological Survey. 
Table 1 Atomization program

\begin{tabular}{clcc}
\hline Step No. & Step & Temperature $/{ }^{\circ} \mathrm{C}$ & Time $/ \mathrm{s}$ \\
\hline 1 & Drying & 120 & 90 \\
2 & Charring & $120-280$ & 35 \\
3 & Charring & 800 & 25 \\
4 & Cooling & 22 & 10 \\
5 & Atomizing & 2100 & 5 \\
6 & Cleaning & 2600 & 4 \\
7 & Cooling & 20 & 10 \\
\hline
\end{tabular}

rapid ascent $(25 \mathrm{~s})$ to $800^{\circ} \mathrm{C}$, so as to minimize a splattering effect when the samples were heated.

Additional equipment included a muffle furnace, a multi-stir plate, a wrist-action shaker, and ultrapure graphite crucibles.

\section{Reagents and materials}

The TOPO and lithium metaborate were of reagent grade, the L-ascorbic acid of biochemical grade, and the MIBK of Ultrex grade; the hydrochloric acid was InstraAnalyzed, suitable for trace-metal analysis.

Solutions: $7.5 \% \mathrm{v} / \mathrm{v} \mathrm{HCl} ; 4 \% \mathrm{w} / \mathrm{v}$ TOPO-MIBK; matrix modifier $=1: 1$ mixture of $2000 \mathrm{mg} / 1$ magnesium nitrate and $6 \%$ ammonium monohydrogenphosphate.

Standard solutions: a stock solution of $1 \mathrm{mg} / \mathrm{l}$ tin in $7.5 \% \mathrm{v} / \mathrm{v} \mathrm{HCl}$ was prepared from a $1000 \mathrm{mg} / 1 \mathrm{com}-$ mercial standard. Aqueous standard tin solutions were prepared by diluting microliter portions of the stock tin solution to volume with $7.5 \% \mathrm{HCl}$ in $100 \mathrm{ml}$ volumetric flasks and spiking with $0.3 \mathrm{~g}$ lithium metaborate. The resultant tin working standards had a concentration range of from $2.5-120 \mu \mathrm{g} / \mathrm{l}$ after extraction into TOPOMIBK.

Reference materials: GSJ reference silicate rocks JGIa, JG-2, JG-3, JGb-1, JB-1a, JB-2, JB-3, JA-1, JA-2, JA-3, JF-1, JF-2, JP-1, JR-1, and JR-2, carbonate rocks JLs-1 and JDo-1, and lake sediment standard JLk-1.

\section{Procedure}

The samples were weighed and mixed with a lithium metaborate fluxing agent in a $3: 1$ ratio of flux to sample and transferred to graphite crucibles. As many as 12 samples were fused simultaneously in a muffle furnace at $925^{\circ} \mathrm{C}$ for $10 \mathrm{~min}$; the resulting molten beads were then transferred into polyethylene beakers containing $100 \mathrm{ml}$ of $7.5 \% \mathrm{v} / \mathrm{v} \mathrm{HCl}$ on a multi-stir plate for dissolution (15 min). In preparation for an analysis of tin, an approximately $40 \mathrm{ml}$ aliquot (by weight) of each sample was taken and added to an $18 \mathrm{~cm}$ screw cap test tube containing $0.75 \mathrm{~g}$ of ascorbic acid. After shaking for $15 \mathrm{~min}$, tin was extracted into a $4 \%$ TOPO-MIBK solution. The organic sample and standard extracts were kept under refrigeration until analysis (may be preserved indefinitely, if sealed tightly).

The analysis for tin with the GFAAS consisted of pipetting $10 \mu \mathrm{l}$ of sample plus a like amount of matrix modifier onto the sample platform of the graphite furnace tube with the AS-60 autosampler, utilizing the atomization program outlined in Table 1. A leastsquares curve was constructed from the absorbance values of the working standards and their weightcorrected concentrations. The raw concentrations $(C)$ of the rock reference materials were determined from the regression curve and then calculated as $\mu \mathrm{g} / \mathrm{g}$ of tin in the rock $\left(C_{\text {(corr) }}\right)$ by correcting for the weight aliquot taken, extraction volume ratio, and weight of sample fused, as follows:

$$
\begin{aligned}
C_{\text {(corr) }}=C( & \mu \mathrm{g} / 1) \times \frac{40.68(\mathrm{~g})}{[\text { Aliquot Wt. }(\mathrm{g})]} \times \frac{0.005(\mathrm{l})}{\mathrm{EVR}} \\
& \times \frac{1}{[\text { Sample Wt. }(\mathrm{g})]},
\end{aligned}
$$

where $C$ is the mean concentration value calculated from the regression curve, 40.68 is the mean weight of a $40 \mathrm{ml}$ sample aliquot, and EVR is the volume ratio of sample aliquot: TOPO-MIBK.

The experimental work had five basic components: Series A-extraction of $0.1 \mathrm{~g}$ samples of reference standards into $10 \mathrm{ml}$ of TOPO-MIBK (4:1 extraction ratio); Series B-extraction of $0.1 \mathrm{~g}$ samples into $5 \mathrm{ml}$ of TOPO-MIBK (8: 1 extraction ratio); Series C-extraction of $0.2 \mathrm{~g}$ samples into $5 \mathrm{ml}$ of TOPO-MIBK $(8: 1$ extraction ratio); Series D--extraction of $0.3 \mathrm{~g}$ samples into $5 \mathrm{ml}$ of TOPO-MIBK; and Series E-extraction of $0.5 / 0.6 \mathrm{~g}$ samples into $5 \mathrm{ml}$ of TOPO-MIBK.

\section{Results and Discussion}

\section{Analytical evaluation}

As the amount of analyte presented to an analytical detector increases, it is to be assumed that both the accuracy and the precision of the analytical results will improve, provided that the analytical measuring capacity of the detector is not exceeded. The task was thus to increase the signal reaching the graphite furnace detector to an optimal level by either increasing the size of the rock sample taken or by concentrating the sample by an increase in the extraction ratio. The relative standard deviation (RSD) values and F-test ratios were calculated for comparing the precision of the methods. The calculated 2 sigma detection limits for Series $\mathrm{A}$ and $\mathrm{C}$, respectively, were $<0.2 \mu \mathrm{g} / \mathrm{g}$ tin and $<0.05 \mu \mathrm{g} / \mathrm{g}$ tin.

The RSD values for Series A and B showed considerable scatter for rocks with a tin concentration $<1.5 \mu \mathrm{g} / \mathrm{g}$. By contrast, for Series $\mathrm{C}$ and $\mathrm{E}$, where respective sample sizes of 0.2 and $0.5 \mathrm{~g}$ were employed, the precision was $10 \%$ or better over the concentration range of $0.36-1 \mu \mathrm{g} / \mathrm{g}$ tin in the rock. Above an analyte concentration of about $0.5 \mu \mathrm{g} / \mathrm{g}$ tin in the rock there was an increasing convergence of the precision values for 0.2 and $0.5 \mathrm{~g}$ rock samples as the tin concentration in the rock increased. Above $1.5 \mu \mathrm{g} / \mathrm{g}$ the precision values for rocks of these two sample sizes were virtually identical for the reference materials examined and averaged about $5 \%$. For rock materials with a tin value of $2.5 \mu \mathrm{g} / \mathrm{g}$ tin 
Table 2 Comparison of experimental values for tin $(\mu \mathrm{g} / \mathrm{g})$ with "working" values (compiled by Govindaraju 7,8 ) for $15 \mathrm{GSJ}$ reference materials plus proposed values for three new GSJ sedimentary rock materials

\begin{tabular}{|c|c|c|c|c|c|c|c|c|}
\hline \multirow{3}{*}{$\mathbf{R M}$} & \multicolumn{5}{|c|}{ Experimental values (this work) } & \multirow{3}{*}{ Best value } & \multicolumn{2}{|c|}{ Working values } \\
\hline & \multirow{2}{*}{$\begin{array}{c}4: 1 \mathrm{EVR} \\
0.1 \mathrm{~g} \\
\text { (A) }\end{array}$} & \multicolumn{4}{|c|}{ 8:1 EVR } & & 1984 & 1989 \\
\hline & & $\begin{array}{l}0.1 \mathrm{~g} \\
\text { (B) }\end{array}$ & $\begin{array}{c}0.2 \mathrm{~g} \\
\text { (C) }\end{array}$ & $\begin{array}{l}0.3 \mathrm{~g} \\
\text { (D) }\end{array}$ & $\begin{array}{l}0.5 \mathrm{~g} \\
(\mathrm{E})\end{array}$ & & & \\
\hline JG-1a & 5.0 & 4.7 & 4.4 & & 4.1 & 4.1 & & 4.2 \\
\hline JG-2 & 3.0 & 2.5 & 2.6 & & 2.5 & 2.5 & & 2.5 \\
\hline JG-3 & 1.2 & 1.3 & 1.1 & & 1.1 & 1.1 & & 1.0 \\
\hline JGb-1 & 0.83 & 0.61 & 0.54 & & 0.42 & 0.42 & & 0.36 \\
\hline JB-1a & 2.4 & 2.0 & 2.1 & & 2.0 & 2.0 & 1.8 & 2.0 \\
\hline JB-2 & 1.3 & 0.77 & 0.73 & & 0.55 & 0.55 & 0.5 & 0.56 \\
\hline JB-3 & 1.5 & 1.3 & 1.2 & & 0.92 & 0.92 & 0.8 & 0.86 \\
\hline JA-1 & 1.0 & 1.0 & 0.86 & & 0.82 & 0.84 & 0.8 & 0.78 \\
\hline JA-2 & 1.6 & 1.4 & 1.8 & & 1.7 & 1.6 & & 1.5 \\
\hline JA-3 & 1.0 & 0.95 & 1.1 & & 1.0 & 1.0 & & 0.9 \\
\hline JF-1 & 0.75 & 0.44 & 0.30 & 0.30 & 0.28 & 0.29 & & 0.3 \\
\hline JF-2 & 1.0 & 0.28 & 0.15 & 0.14 & 0.16 & 0.15 & & 0.1 \\
\hline JP-1 & 0.42 & 0.22 & 0.10 & & $0.12^{\mathrm{a}}$ & 0.11 & & 0.05 \\
\hline JR-1 & 3.4 & 3.0 & 3.1 & & 2.9 & 3.0 & 2.6 & 2.7 \\
\hline JR-2 & 4.1 & 3.8 & 3.8 & & 3.9 & 3.8 & 2.9 & 3.2 \\
\hline JLk-1 & 7.6 & 6.4 & 6.4 & & 5.8 & 5.8 & & \\
\hline JLs-1 & 0.31 & 0.24 & 0.06 & & $0.10^{\mathrm{a}}$ & 0.08 & & \\
\hline JDo-1 & 0.56 & 0.24 & $<0.05$ & & $0.10^{\mathrm{a}}$ & 0.10 & & \\
\hline
\end{tabular}

a. $0.6 \mathrm{~g}$ sample. RM: reference material. EVR: extraction volume ratio of rock solution to TOPO-MIBK.

(JR-1) or better the precision values for $0.1 \mathrm{~g}$ samples concentrated at an 8:1 extraction ratio (Series B) approximate those for the $0.2 \mathrm{~g}$ and $0.5 \mathrm{~g}$ samples and above $4 \mu \mathrm{g} / \mathrm{g}$ tin the RSD values for all series converge. Below values of $0.36 \mu \mathrm{g} / \mathrm{g}$ tin in the rock the precision deteriorates as the detection limit is approached, but in two instances (JLs-1 and JF-1) the precision was $10 \%$ or better for Series $\mathrm{D}$ and $\mathrm{E}$.

Examination of Table 2 validates the worth of Series D and $\mathrm{E}$. This Table summarizes the experimental values for the five series, lists the "best" values for this work, and compares the results with the recommended working values compiled by Govindaraju ${ }^{7,8}$ from work by Terashima and $\mathrm{Ando}^{9}$ and Ando et al. ${ }^{10}$ The best values were chosen from the experimental values with the best fit, analytically and statistically, with the working values. Table 3 summarizes the statistical evaluation of the "best" value by indicating which Series' values are acceptable for consideration (not significantly different from one another at the $95 \%$ confidence level as a minimum).

Examining Table 2, in five cases the "best" value corresponded to the Series E values. For the other reference materials the "best" value corresponded to the arithmetic mean of two or more Series' results with only JG-3, JA-2, and JA-3 utilizing all four series values. Other than these three reference materials, Series-A values were always greater than the normative and/or "best" values. The principal reason for this is most probably the smaller analytical signal for Series-A materials (Series $A /$ Series $E=1 / 10$ ) and its proximity to
Table 3 Analysis of variance between extraction series $(\mathrm{A}, \mathrm{B}, \mathrm{C}, \mathrm{D}, \mathrm{E})$

\begin{tabular}{lcccccc}
\hline & \multicolumn{5}{c}{$F$-Test (0.95 \& 0.99 confidence levels) } \\
\cline { 2 - 7 } RM & A, B, C, E & B, C, E & A, E & B, E & C, E & D, E \\
\hline JG-1a & $31 \mathrm{~S}$ & $14 \mathrm{~S}$ & & & $9.4 \mathrm{~S}$ & \\
JG-2 & $9.9 \mathrm{~S}$ & 3.1 & $19 \mathrm{~S}$ & & $6.3(\mathrm{~S})$ & \\
JG-3 & $4.8(\mathrm{~S})$ & $11 \mathrm{~S}$ & & $14 \mathrm{~S}$ & 0.47 & \\
JGb-1 & $19 \mathrm{~S}$ & $7.9 \mathrm{~S}$ & & & $44 \mathrm{~S}$ & \\
JB-1a & & 1.4 & $45 \mathrm{~S}$ & & 2.8 & \\
JB-2 & & $16 \mathrm{~S}$ & & & $84 \mathrm{~S}$ & \\
JB-3 & & $31 \mathrm{~S}$ & & & $43 \mathrm{~S}$ & \\
JA-1 & $4.6 \mathrm{~S}$ & $12.5 \mathrm{~S}$ & & $17 \mathrm{~S}$ & 3.0 & \\
JA-2 & $7.0 \mathrm{~S}$ & $11 \mathrm{~S}$ & 3.5 & & 4.3 & \\
JA-3 & 2.4 & $3.9(\mathrm{~S})$ & & & $7.0(\mathrm{~S})$ & \\
JF-1 & $8.4 \mathrm{~S}$ & 0.9 & & $12.5 \mathrm{~S}$ & 1.2 & 3.7 \\
JF-2 & $7.9 \mathrm{~S}$ & 1.1 & & $7.4 \mathrm{~S}$ & 0.56 & 3.3 \\
JP-1 & & $11.5 \mathrm{~S}$ & & $13 \mathrm{~S}$ & 0.95 & \\
JR-1 & $7.5 \mathrm{~S}$ & 8.5 & & 0.34 & $14 \mathrm{~S}$ & \\
JR-2 & $3.7(\mathrm{~S})$ & 1.7 & 2.0 & & $4.8(\mathrm{~S})$ & \\
JLk-1 & $116 \mathrm{~S}$ & $26 \mathrm{~S}$ & & & $80 \mathrm{~S}$ & \\
JLs-1 & & $16 \mathrm{~S}$ & & $13 \mathrm{~S}$ & $8.9(\mathrm{~S})$ & \\
JDo-1 & & & & $22 \mathrm{~S}$ & & \\
\hline
\end{tabular}

a. For RM's JF-1 \& JF-2 extraction series B, C, D, E and C, $D, E$ were compared, respectively, rather than series $A, B, C$, $\mathrm{E}$ and $\mathrm{B}, \mathrm{C}, \mathrm{E}$ for their analysis of variance. S: significant difference at both $95 \%$ \& $99 \%$ confidence levels. (S): significant difference at $95 \%$ confidence level only.

the detection limit. Thus the error bars in some cases might overlap with the latter. In the case of the three 
exceptions (JG-3, JA-2, and JA-3) a greater sampling homogeneity for tin is implied relative to the other reference materials, since the total tin content of these three only approximates $1 \mu \mathrm{g} / \mathrm{g}$.

Prior to initiating Series D and E, only six of the GSJ reference materials, namely, JG-2, JG-3, JB-1a, JA-2, $\mathrm{JA}-3$, and JF-1, exhibited agreement within $\pm 0.1 \mu \mathrm{g} / \mathrm{g}$ of the recommended literature values. Surprisingly, the implementation of Series D and E effected no notable value changes for rocks with a total tin concentration $<0.5 \mu \mathrm{g} / \mathrm{g}$, except for JGb-1 and JB-2. Among the rocks with tin concentrations $>0.5 \mu \mathrm{g} / \mathrm{g}, \mathrm{JG}-1 \mathrm{a}, \mathrm{JB}-3$, and JA-1 all exhibited closer agreement with the literature values. JGb-1, JB-2, JB-3, and JA-1, evinced lower values which were within $0.04-0.06 \mu \mathrm{g} / \mathrm{g}$ of the literature values. The similar positive bias of JF-2 and JP-1 remained unchanged. Since there is one instance of negative bias (JG-1a), and several instances of no bias, it remains an open question as to whether the positive biases are real, represent experimental error, or whether these values are more nearly accurate than the literature values. JR-1 and JR-2 showed no real change from Series B and C results, which differed by 0.3 and $0.6 \mu \mathrm{g} /$ $\mathrm{g}$, respectively, from the literature values. The concurrent determination of tin in the USGS standard RGM-1 yielded values of $4.1 \& 4.4 v s$. the recommended literature value of 4.1. This suggests that other independent data are needed to ascertain the "best" value for the rhyolites.

\section{Statistical evaluation}

One-sided analysis of variance tests (STATGRAF software) were performed on the analytical data in order to obtain a statistical evaluation. Our source of critical $F$-test ratios was Natrella. ${ }^{11}$ For the various Series the exhibited failures to meet the null hypothesis were few in number and appeared to be random. The low magnitude of the $F$-test values validates the homogeneity of the reference materials with regard to tin.

Table 3 measures the variance of the individual experimental Series A, B, C, D and E from one another, and thus serves as a measure of their equivalency or relative accuracy. The statistical data in the table demonstrate that there are significant statistical and, hence, analytical differences between Series A, B, C, and Series D and E. In the comparison of Series $C$ and $E$, the failure of JGb-1, JB-2, and JB-3 to meet the statistical criteria at either confidence level further validates the conclusion reached in the analytical evaluation section that rock materials having tin concentrations below the $1 \mu \mathrm{g} / \mathrm{g}$ criteria should require a $0.5 \mathrm{~g}$ sample.

Further statistical scrutiny was applied using the Sutarno/Steger criteria for methods validation for standard reference materials. ${ }^{12}$ Their criterion for accuracy is given by the following equation:

$$
\left|X-A_{\mathrm{c}}\right|<4 S_{\mathrm{w}},
$$

where $X$ is the SRM mean value, $A_{\mathrm{c}}$ is the certified/ recommended value, and $S_{\mathrm{w}}$ means within-laboratory standard deviation. Using this criteria, all but six of the 62 mean values determined by the five series of experiments for the 15 rock reference materials would be judged to be accurate. Using the more rigid criteria of $2 S_{\mathrm{w}}$, significantly more entities fail the accuracy test, particularly Series A, B and C entities. Three of the six failures for Series $\mathrm{C}$, however, are for rocks with contents $<1 \mu \mathrm{g} / \mathrm{g}$ tin, which again validates the assumption concerning the necessity for a $0.5 \mathrm{~g}$ sample in this range of tin concentration. It is evident that using a more rigid $2 S_{\mathrm{W}}$ criteria is preferrable. When the Sutarno/Steger test is applied to the listed "best" values in Table $2 v s$. the literature values, only JGb-1 fails both the $4 S_{\mathrm{W}}$ and $2 S_{\mathrm{W}}$ criteria, while JR-1 and JR-2 meet only the former criteria.

\section{New standards}

In 1987 a "Sedimentary Rock Series" was prepared and issued by the GSJ. It consists of JLk-1, a freshwater lake sediment from Lake Biwa in Shiga Prefecture; JLs-1, a limestone from the Garo Mine on Hokkaido; and JDo-1, a dolomite from the Tochigi Prefecture. Analytical data for major and minor constituents (not including tin) was reported by Ando et al..$^{13}$ This work found the total tin content for JLk-1 to be quite high, namely, $5.8 \mu \mathrm{g} / \mathrm{g}$. As expected, the tin contents of the limestone and dolomite were quite low, 0.08 and $0.10 \mu \mathrm{g} /$ $\mathrm{g}$ respectively, and required larger amounts of sample for their accurate determination.

In conclusion, optimization of an GFAAS-extraction method for tin reported by Elsheimer and Fries ${ }^{6}$ has resulted in a procedure capable of yielding accurate and precise results for rocks and sedimentary materials. Optimally, rock concentrations of $0.5 \mathrm{~g}$ sample should be taken and an 8:1 extraction ratio of sample aliquot: TOPO-MIBK employed. For samples containing $<1 \mu \mathrm{g} / \mathrm{g}$ tin the use of a $0.5 \mathrm{~g}$ sample is an absolute requirement. The use of larger extraction ratios would be impractical from the perspective of the diminished volume of analyte available for analysis. Overall, the agreement of the "best" values of this work with the recommended literature values for $15 \mathrm{GSJ}$ rock reference materials is excellent and meets the statistical criteria. The values of 13 of the standards agree within $0.1 \mu \mathrm{g} / \mathrm{g}$. The remaining two, JR-1 and JR-2, differ by 0.3 and $0.6 \mu \mathrm{g} / \mathrm{g}$, respectively, and would seem to require additional validation of their "true" tin content. The values reported here for the new reference materials JLk1 , JLs-1, and JDo-1 should have validity in light of the quality of data reported for the other 15 standards.

The author wishes to acknowledge the assistance of Jean Kane (formerly of the U.S. Geological Survey) of the National Institute of Standards and Technology with the statistical evaluations. 


\section{References}

1. H. Fritzsche, W. Wegscheider, G. Knapp and H. M. Ortner, Talanta, 26, 219 (1979).

2. E. Lundberg, B. Bergmark and W. Frech, Anal. Chim. Acta, 142, 129 (1982).

3. E. Pruszkowska, D. C. Manning, G. R. Carnrick and W. Slavin, At. Spectrosc., 4, 87 (1983).

4. J. Long-zhu, At. Spectrosc., 5, 91 (1984).

5. L. Zhou, T. T. Chao and A. L. Meier, Talanta, 31, 73 (1984).

6. H. N. Elsheimer and T. S. Fries, Anal. Chim. Acta, 239, 145 (1990).

7. K. Govindaraju, Geostand. Newsl., 8 (special issue), 32 (1984).
8. K. Govindaraju, Geostand. Newsl., 13 (special issue), 78 (1989).

9. S. Terashima and A. Ando, Geostand. Newsl., 11, 75 (1987).

10. A. Ando, N. Mita and S. Terashima, Geostand. Newsl., 11, 159 (1987).

11. M. G. Natrella, "Experimental Statistics", Handbook 91, U.S. Department of Commerce, NBS, Washington, D.C., 1966.

12. R. Sutarno and H. F. Steger, Talanta, 32, 439 (1985).

13. A. Ando, T. Okai, Y. Inouchi, T. Igarashi, S. Sudo, K. Marumo, S. Itoh and S. Terashima, Bull. Geolog. Survey Jpn., 41, 27 (1990).

(Received February 16, 1993)

(Accepted June 23, 1993) 